\title{
Spontaneous intramural haematoma of the oesophagus
}

\section{GIANNI BIAGI, GIOVANNI CAPPELLI, LUCIO PROPERSI, ADALBERTO GROSSI}

From the Department of Thoracic and Cardiovascular Surgery, University of Siena Medical School, Siena, and Department of General Surgery, Sarteano, Italy

Spontaneous intramural dissection of the oesophagus is a rare condition and few cases have been published. Elderly women are most frequently affected, whereas in the Mallory-Weiss and Boerhaave syndrome there is a preponderance of men. Retrosternal pain, haematemesis, and the radiological findings of the barium swallow have always been sufficient for the diagnosis. We report a case, however, which differs from those previously published in that the barium swallow was normal and the dissection affected only the muscular layer without any tear in the mucosa.

\section{Case report}

A 58-year-old woman who had been taking aspirin for a few days suddenly suffered retrosternal and epigastric pain

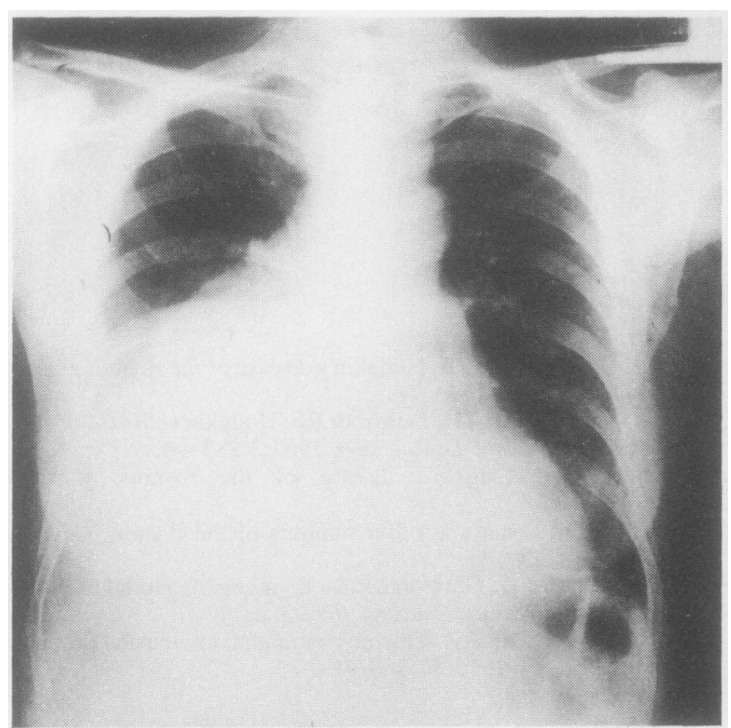

Fig 1 Chest radiograph showing a right paramediastinal shadow with a sharp outline, caused by an encapsulated mediastinal haematoma.

Address for reprint requests: Professor A Grossi, Department of Thoracic and Cardiovascular Surgery, University of Siena Medical School, Siena, Italy.

Accepted 2 November 1982 with shock. Her electrocardiogram was unremarkable but $\overrightarrow{\vec{x}}$ laboratory data showed a haemoglobin concentration of $\omega$ $7.4 \mathrm{~g} / 100 \mathrm{ml}$. The chest radiograph showed a large right of lower paramediastinal shadow with a sharp outline (fig 1). is

The patient was then transferred to our institute, where a new radiograph and a barium swallow showed a right $\circ$ pleural effusion and displacement of the middle and lower 3 oesophagus to the left, without alteration of the lumen or the mucous membrane (fig 2). The appearances at the subsequent oesophagoscopy were unremarkable, but right thoracentesis showed the presence of a haemothorax.

At operation there was a large quantity of blood in the pleura with a large laceration of the mediastinal pleura and massive necrosis of the muscular layer of the oesophagus, which had been dissected off the mucosal layer by a wide-

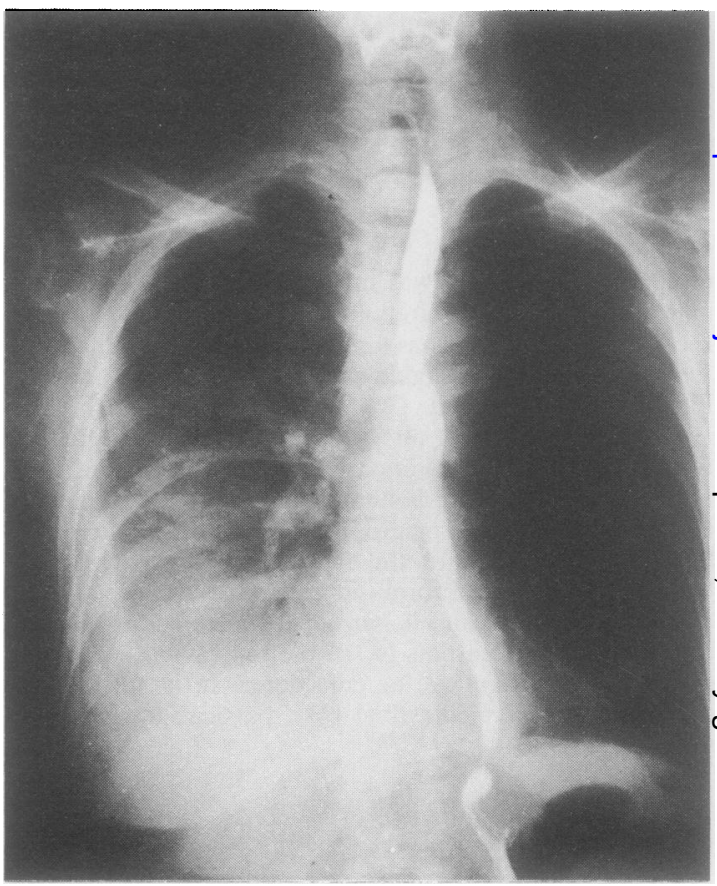

Fig 2 Chest radiograph and barium swallow showing a right haemothorax and displacement of the lower oesophagus to the lefi, with a normal mucosal profile. 
spread haematoma over the whole length of the thoracic oesophagus. After resection of nearly all the muscular layer no damage to the mucous membrane was observed and oesophagectomy was not required.

The patient was discharged in good health, with a normal barium swallow, on the 13th day after admission. Five months later a repeat barium swallow and oesophagoscopy showed no alteration of the oesophageal lumen or abnormality of the mucosa.

\section{Discussion}

Intramural rupture and spontaneous intramural dissection of the oesophagus are probably more frequent than the published cases suggest. The onset of a severe or rapidly worsening retrosternal and epigastric pain associated with modest haematemesis and dysphagia has characterised almost all the observed cases and has led, after a barium swallow, to the diagnosis. ${ }^{1-4}$

The interest of our case results not just from the presence of a spontaneous intramural dissection but also from the unusual presentation and pathological findings. The absence of dysphagia and haematemesis and the normal findings at oesophagoscopy and barium swallow led us to exclude an oesophageal lesion. The finding of an intramural haematoma of the oesophagus with extensive necrosis of the muscular layer was therefore unexpected. In the other reported cases there has always been a mucosal tear with submucosal dissection but without lesions of the muscular layer. Furthermore, only Borrie and Sheat ${ }^{5}$ have reported a case with pleural effusion and no cases have been described with a normal barium swallow.

The aspirin ingestion may have caused the bleeding, as in a case observed by Smith et $a l,{ }^{6}$ but it is difficult to explain why the oesophagus should be the sole target organ and why there were no mucosal lesions in the oesophagus, stomach, or duodenum despite the gravity of the bleeding and the extent of the muscular necrosis.

As with other reported cases the treatment was conservative and this produced a satisfactory result, even though the oesophagus was almost totally deprived of its muscular layer.

\section{References}

' Barone JE, Robilotti JG, Comer JV. Conservative treatment of spontaneous intramural perforation (or intramural hematoma) of the oesophagus. Am J Gastroenterol 1980;74:165-7.

${ }^{2}$ Kerr WF. Spontaneous intramural rupture and intramural haematoma of the oesophagus. Thorax 1980;35:890-7.

${ }^{3}$ Marks IN, Keet AD. Intramural rupture of the oesophagus. $\mathrm{Br}$ Med J 1968;iii:536-7.

4 Morritt GN, Walbaum PR. Spontaneous dissection of the oesophagus. Thorax 1980;35:898-900.

${ }^{5}$ Borrie J, Sheat J. Spontaneous intramural oesophageal perforation. Thorax 1970;25:294-300.

- Smith G, Brunnen PL, Gillanders LA, Teo HS. Oesophageal apoplexy. Lancet $1974 ; \mathrm{ii}: 390-2$. 